\title{
Effects of Supraphysiological Doses of Testosterone Cypionate and Stanozolol on Neuronal Density of Basolateral and Medial Amygdala and on the Anxious Behavior of Mice
}

\author{
Melissa Ribeiro ${ }^{1}$ Ariane Freitas ${ }^{1}$ Bruno Damião ${ }^{1}$ Wagner Costa Rossi Junior ${ }^{2}$ Flávia da Ré Guerra ${ }^{1}$ \\ Evelise Aline Soares ${ }^{1} \quad$ Petrus Pires Marques $^{2} \quad$ Alessandra Esteves $^{1}$ \\ ${ }^{1}$ Department of Anatomy, Universidade Federal de Alfenas, Alfenas, \\ MG, Brazil \\ 2 Departament of Morphology, Universidade José do Rosário Vellano, \\ Unifenas, Alfenas, MG, Brazil \\ Address for correspondence Alessandra Esteves, PhD, Departamento \\ de Anatomia, Universidade Federal de Alfenas, Rua Gabriel Monteiro \\ da Silva, $n^{\circ} 700$, Centro, Alfenas, MG, Brasil, CEP 37130-000. \\ (e-mail: aesteves015@gmail.com).
}

J Morphol Sci 2019;36:115-121.

\begin{abstract}
Keywords

- anabolic-androgenic steroids

- basolateral amygdala

- medial amygdala

- anxiety

- density neuron

Supraphysiological doses of anabolic-androgenic steroids (AAS) have been associated to possible nerve tissue damage and behavioral effects. Considering the lack of knowledge of the neural aspects involved in these behavioral alterations, this work aimed to analyze the anxious behavior response or aggressiveness, besides quantifying the neuronal density of the basolateral amygdala (BLA) and of the ventral posterior nucleus (VPN) of the medial amygdala. The animals received doses of testosterone cypionate (CT Group) and stanozolol (ST Group) twice a week for 33 days. The effects of chronic administration of AAS related to anxious behavior (as determined by the elevated plus maze [EPM] test) in male animals are observed in a lower number of entries $(<45.25 \%)$, and a shorter staying time spent in the open arms $(<41.9 \%)$ was observed in the ST. In female animals, a longer staying time spent in the closed arms of the EPM test was observed in the CT $(>15 \%)$ as well as a shorter staying time spent in the open arms for $\mathrm{CT}(<17.1 \%)$ also to ST $(<52.1 \%)$. Regarding the neuronal density in BLA, a significant reduction in neuronal density of male animals (17.55\%) was observed only in CT, whereas for females, significant differences were found in CT (19.16\%) and ST (18.36\%). The reduction of neuronal density in VPN in male animals was $13.55 \%$ in CT and $17.68 \%$ in ST, whereas in group of females it was $13.53 \%$ and $14.32 \%$, respectively for $\mathrm{CT}$ and $\mathrm{ST}$. Therefore, the two steroids used in this experiment were able to significantly reduce neuronal density in two analyzed areas, regardless of sex, suggesting that indiscriminate use of these substances causes death of brain amygdala neurons.
\end{abstract}

\section{Introduction}

Abusive use of anabolic-androgenic steroids (AAS) is based on supraphysiological doses that are 10 to 100 times greater than therapeutic doses, ${ }^{1,2}$ and which have been associated

received

August 22, 2018

accepted

March 28, 2019
DOI https://doi.org/

10.1055/s-0039-1688809. ISSN 2177-0298. with a wide spectrum of adverse physical and psychic effects. Little is known about the effect of AAS in the human brain, with reports of changes in behavior, such as aggressiveness, anxiety and depression, among others. ${ }^{3-5}$
Copyright $(2019$ by Thieme Revinter Publicações Ltda, Rio de Janeiro, Brazil
License terms

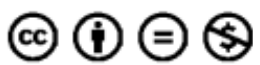


Some studies have shown that AAS may have deleterious effect on the central nervous system (CNS). ${ }^{6}$ The few in vitro data obtained suggest that the influence of androgenic drugs on neurodegeneration depends critically on the treatment regimen, concentration and cell phenotype. A single application of testosterone in supraphysiological concentration promoted cell death by apoptosis in nerve cells by means of altering their $\mathrm{Ca}^{2+}$ signaling. ${ }^{7}$

Recent animal models have demonstrated that chronic use and abuse of stanozolol have reduced levels of brainderived neurotrophic factor (BDNF) and dopamine in the hippocampus and prefrontal cortex of rodents, in addition to the reduction in glucocorticoid receptor expression in the hippocampus and in plasma, and an increase in basal morning plasma cortisol levels. These metabolic changes have been related to mood disorders, such as depression. ${ }^{8,9}$

As the monoaminergic system regulates aggression, sexual behavior, fear and anxiety, one can suggest a possible correlation between changes in the monoamines generated by AAS and behavioral alterations and mood disorders. 9,10

From the above mentioned, it is evident that there are considerable negative neurological effects due to abusive and/or chronic use of AAS that can lead to serious complications and damages, both physical and behavioral. Regarding the lack of knowledge of the neural mechanisms involved in the wide range of deleterious effects that may involve the CNS, it is necessary to carry out new research aiming to elucidate the underlying brain mechanisms associated to them.

\section{Material and Methods}

Ninety-two Swiss mice from the Central Biotery of the Universidade Federal de Alfenas (UNIFAL-MG) were used, with 46 being male and 46 female, $\sim 90$ days old (young adults), weighting between 40 and $50 \mathrm{~g}$. All animals were fed with commercial ration and water ad libitum (at will) and kept in a 12-hour light-dark cycle. The animals were divided as follows:

CT group - Animals receiving testosterone cypionate (SigmaPharm Laboratories, Philadelphia, Pensilvania, USA) at a dose of $0.8 \mathrm{mg} / \mathrm{kg} /$ day.

ST group - Animals receiving stanozolol (Winstrol Depot [Winthrop Chemical Company, New York, NY, USA]) at a dose of $1.8 \mathrm{mg} / \mathrm{kg} /$ day.

Control group - Animals receiving sterile saline solution at $0.9 \%$ at a dose of $0.05 \mathrm{ml} /$ day.

The treatment consisted of intraperitoneal (IP) injection of the drugs to be tested for 33 days, with applications performed twice a week. On intercalated days, they were submitted to swimming for an initial period of 5 minutes, gradually increasing up to 15 minutes. The swimming was performed in a container measuring $43 \times 34 \times 26 \mathrm{~cm}$, containing in its interior water in the temperature of 24 to $26^{\circ} \mathrm{C}$ to the edge. Swimming training was performed in an attempt to generate the same stress conditions as bodybuilding. From the $33^{\text {rd }}$ day of treatment, the elevated plus maze (EPM) test was performed in all groups to study the effects of these substances on the anxiety level of the animals. $^{11,12}$

After the days of behavioral testing, the animals were euthanized by inhalation of isoflurane for later craniotomy. The brains were removed entirely, washed in saline solution and fixed in $4 \%$ paraformaldehyde in phosphate buffer for 24 hours. After this period, the material underwent the conventional histological processes: alcohol dehydration, xylol diaphanization and paraffin inclusion.

From each brain so obtained, serial and homotypic samples were taken in frontal sections ${ }^{13,14}$ with a thickness of $7 \mu \mathrm{m}$ in a Yidi YD-315 microtome. To evaluate the areas selected for the study, the material was stained with Cresyl violet. ${ }^{14,15}$ The determination of the studied areas matches the representation of plate 43 of Franklin and Paxinos' mouse brain stereotactic atlas. ${ }^{15,16}$ For the quantitative analysis of neuron body cells, the simple random sample counting method was used. ${ }^{17-19}$ Each division of the amygdala (basolateral amygdala [BLA] or ventral posterior nucleus [VPN]) had two areas quantified per hemisphere, totaling four areas per section. To avoid counting the same cell more than once, 3 semi-serial sections per animal were analyzed, totaling 12 histological fields per nucleus studied for each animal. As 2 divisions (BLA) and (VPN) were quantified, a total of 24 areas per animal were obtained. Thus, for the sample used, a total of 960 areas was quantified at a $400 \mathrm{X}$ magnification. All analyzes were performed by means of the software Axiovision 4 Module Interactive Measurement (Carl Zeiss Microscopy LLC, Thornwood NY, USA), an analyzing image system, coupled to the AxioScope A1 microscope (Carl Zeiss Microscopy LLC).

The study represents a completely randomized design (CRD); therefore, the statistical analysis was performed through a one-way analysis of variance (ANOVA) followed by Tukey averages comparison test. Values of $p<0.05$ were considered as indicative of significance.

\section{Ethics Statement}

This work is in accordance with the ethical principles of experiment animal use and has been approved by the Commission for Ethics in Animal Experimentation of UNIFAL-MG, under the registration number 505/2013.

\section{Results}

The effects of chronic administration of AAS related to anxious behavior (determined by the EPM test) in male animals are shown in -Fig. 1. A lower number of entries $(<45.25 \%)$ and a shorter staying time spent in the open arms $(<41.9 \%)$ of the EPM were observed in the stanozolol (Winstrol Depot) group when compared with the control group (-Table 1). These data indicate a greater anxiogenic response to stanozolol (Winstrol Depot) in the male animals group in relation to the control. 

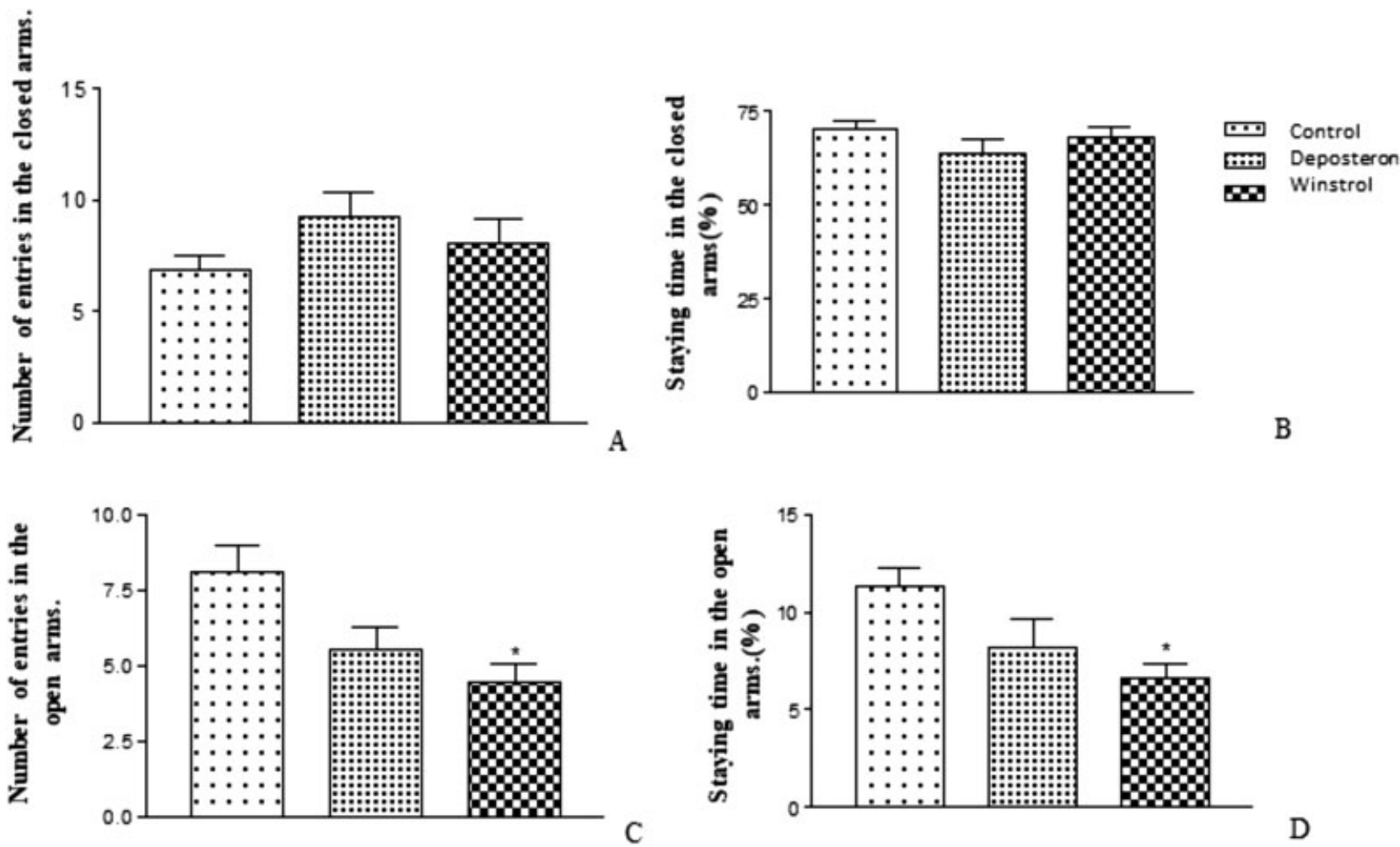

Fig. 1 Graphs illustrating analyzed elevated plus maze test parameters (male animals). Effect of testosterone cypionate (Deposteron), stanozolol (Winstrol Depot) or saline solution administration in relation to the number of entries in the closed arm (A), staying time in the closed $\operatorname{arm}(B)$, number of entries in the open $\operatorname{arm}(C)$ and staying time in the open $\operatorname{arm}(\mathrm{D})$. Means and respective standard deviations $\left({ }^{*}=p<0.01\right)$ are depicted in relation to the control group.

The effects of chronic administration of AAS related to anxious behavior (EPM) in female animals are shown in - Fig. 2. A longer staying time spent in the closed arms of the EPM was observed for the testosterone cypionate (Deposteron) group (>15\%) in relation to the control one, as well as a shorter staying time spent in the open arms of the EPM for the testosterone cypionate (Deposteron) group (< $17.1 \%$ ) when compared with the control and the stanozolol (Winstrol Depot) groups $(<52.1 \%)$. These data indicate a higher anxiogenic response to testosterone cypionate (Deposteron) in the female animals group when compared with the control group (-Table $\mathbf{1}$ ).

In relation to neuronal density in the basolateral amygdala (ABL), a decrease in the number of neuron body cells in the testosterone cypionate (Deposteron) (17.55\%) male animals group was observed when compared with the control group, as shown in - Fig. $\mathbf{3 A}$ and - Table 2. However, in female animals, significant differences were found in

Table 1 Number of entries and staying time in the arms of the elevated plus maze (EPM)test

\begin{tabular}{|l|l|l|l|l|}
\hline & $\begin{array}{l}\text { Number of entries } \\
\text { (open arms) }\end{array}$ & $\begin{array}{l}\text { Number of entries } \\
\text { (closed arms) }\end{array}$ & $\begin{array}{l}\text { \% staying time } \\
\text { (open arms) }\end{array}$ & $\begin{array}{l}\text { \% staying time } \\
\text { (closed arms) }\end{array}$ \\
\hline \multicolumn{5}{|l|}{} \\
\hline Male & $8.11^{\mathrm{a}}$ & $6.88^{\mathrm{a}}$ & $11.34^{\mathrm{a}}$ & $70.28^{\mathrm{a}}$ \\
\hline Control & $5.57^{\mathrm{a}}$ & $9.28^{\mathrm{a}}$ & $8.2^{\mathrm{a}}$ & $63.81^{\mathrm{a}}$ \\
\hline Deposteron & $4.44^{\mathrm{b}}(<45.25 \%)$ & $6.58^{\mathrm{b}}(<41.9 \%)$ & $68.12^{\mathrm{a}}$ \\
\hline Winstrol & $8.00^{\mathrm{a}}$ & \multicolumn{5}{|l|}{} \\
\hline Female & $7.1^{\mathrm{a}}$ & $8.04^{\mathrm{a}}$ & $65.46^{\mathrm{a}}$ \\
\hline Control & $6.2^{\mathrm{a}}$ & $3.85^{\mathrm{b}}(<52.1 \%)$ & $75.64^{\mathrm{b}}(>15 \%)$ \\
\hline Deposteron & $6.00^{\mathrm{a}}$ & $6.5^{\mathrm{a}}(<17.1 \%)$ & $70.63^{\mathrm{a}}$ \\
\hline Winstrol & $5.7^{\mathrm{a}}$ & $8.1^{\mathrm{a}}$ & $6.66^{\mathrm{b}}$ & \\
\hline
\end{tabular}

Different letters in superscript refer to statistical difference using Tukey test at the significance level of $5 \%$. 


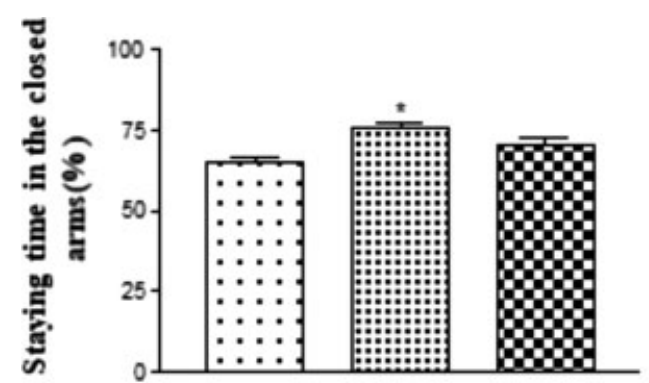

A
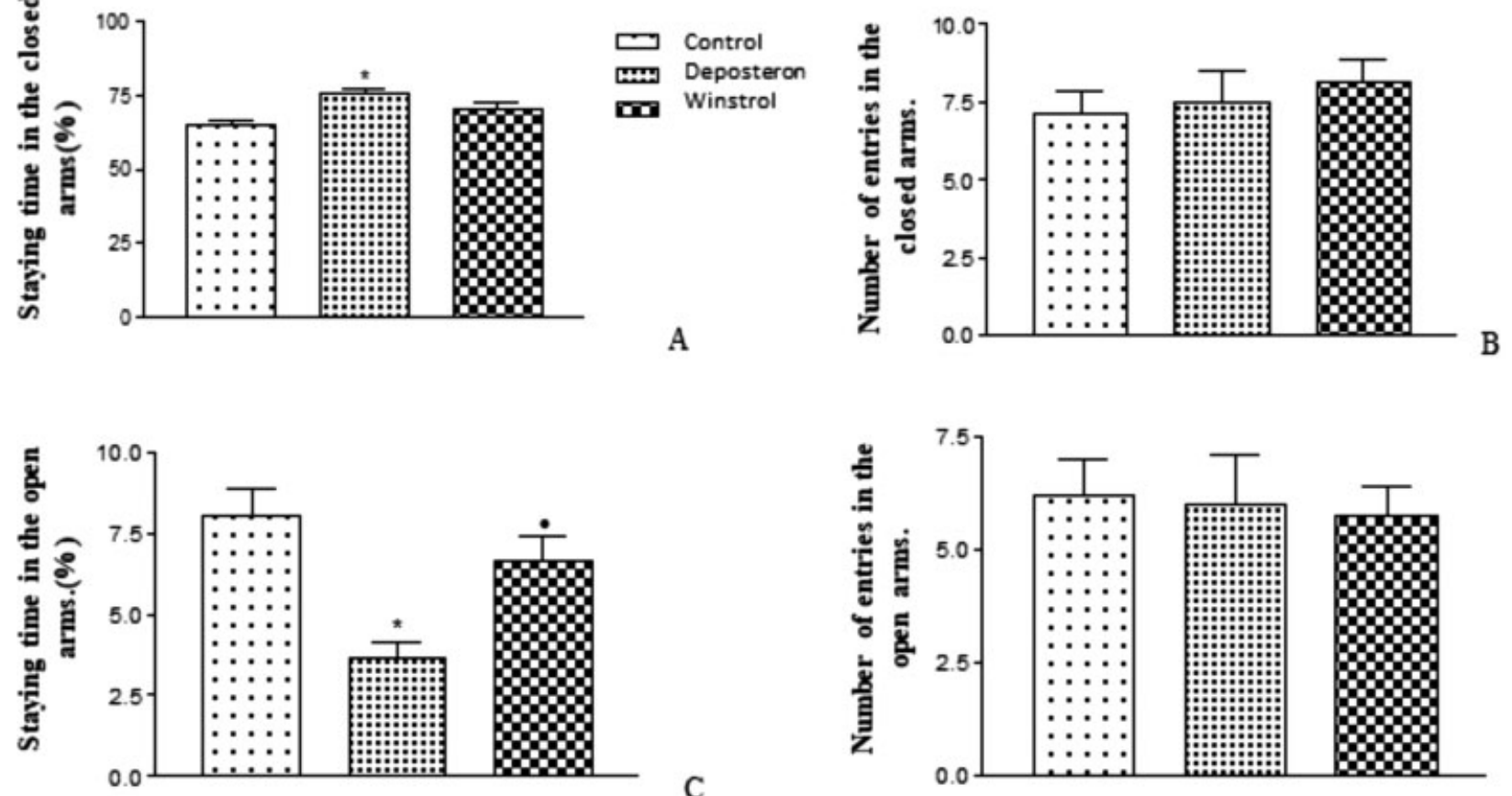

C

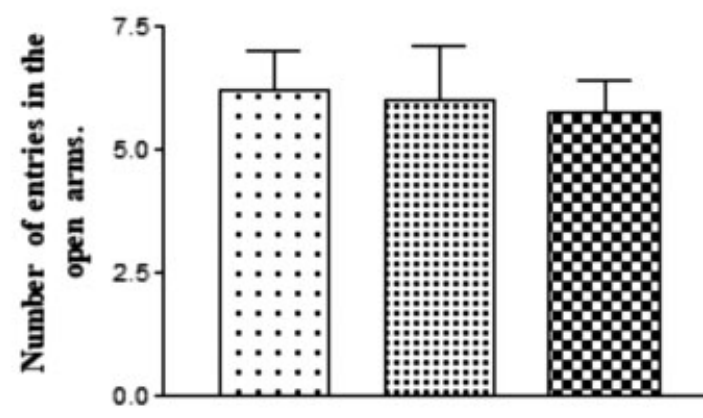

Fig. 2 Graphs illustrating analyzed elevated plus maze test parameters (female animals). Effect of testosterone cypionate (Deposteron), stanozolol (Winstrol Depot) or saline solution administration in relation to the number of entries in the closed arm (A), staying time in the closed $\operatorname{arm}(B)$, number of entries in the open $\operatorname{arm}(C)$ and staying time in the open arm (D). Means and respective standard deviations $\left({ }^{*}=p<0.01\right)$ are depicted in relation to the control group $(\bullet=p<0.05$ is in relation to stanozolol group).
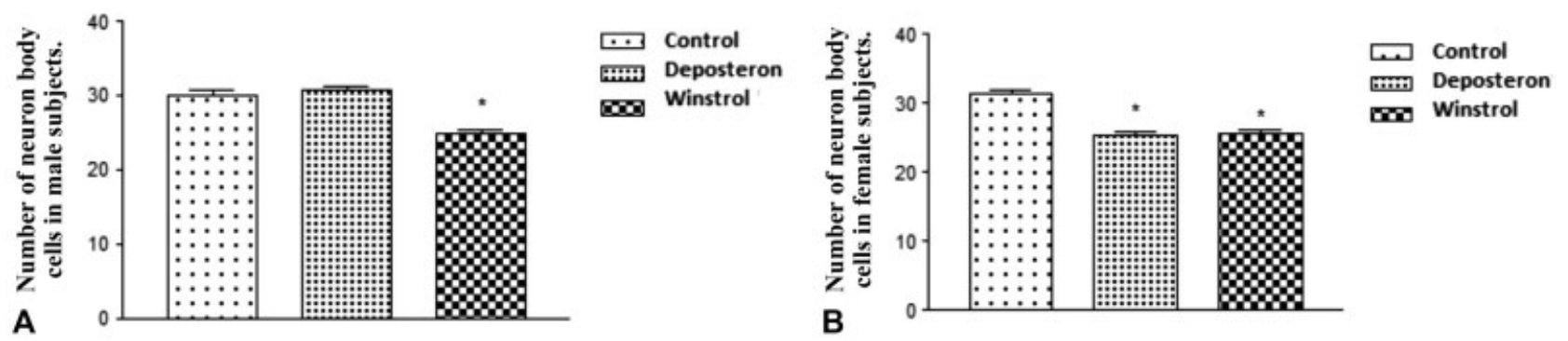

Fig. 3 Neuron body cells counting in the basolateral amygdala (BLA) of male and female animals. (A) shows comparative graphs of neuronal density in BLA of male mice in each analyzed experimental group $\left({ }^{*}=p<0.001\right)$ for testosterone cypionate in relation to the control group. (B) shows comparative graphs of neuronal density in BLA of female mice in each analyzed experimental group $\left({ }^{*}=p<0.001\right)$ for testosterone cypionate and stanozolol in relation to the control group.

Table 2 Mean of basolateral amygdala and percentage of reduction neuron cells quantification

\begin{tabular}{|l|l|l|}
\hline Groups & $\begin{array}{l}\text { Mean } \\
\text { BLA neuron cell }\end{array}$ & Percentage of reduction \\
\hline Male & \multicolumn{2}{|l|}{} \\
\hline Control & $30.07^{\mathrm{a}}$ & - \\
\hline Deposteron & $30.79^{\mathrm{a}}$ & - \\
\hline Winstrol & $24.79^{\mathrm{b}}$ & $17.55 \%$ \\
\hline Female & \multicolumn{2}{|l}{} \\
\hline Control & $31.36^{\mathrm{a}}$ & - \\
\hline Deposteron & $25.35^{\mathrm{b}}$ & $19.16 \%$ \\
\hline Winstrol & $25.60^{\mathrm{b}}$ & $18.36 \%$ \\
\hline
\end{tabular}

Abbreviation: BLA, basolateral amygdala.

BLA neuron cells quantification exhibited as mean value.

Different letters in superscript refer to statistical difference using Tukey test at the significance level of $5 \%$. both testosterone cypionate (Deposteron) (19.16\%) and stanozolol (Winstrol Depot) (18.36\%) groups when compared with the control group, as shown in -Fig. 3B and - Table 2.

The decrease in neuronal density in the ventral posterior nucleus (VPN) of the medial amygdala was observed in both testosterone cypionate (Deposteron) and stanozolol (Winstrol Depot) groups when compared with the control group, for male (Deposteron-13.55\% and Winstrol Depot-17.68\%) and female animals (Deposteron 13.53\% and Winstrol Depot 14.32\%), as shown in -Fig. 4 and -Table 3.

\section{Discussion}

From the general analysis of the results in the EPM test, we can suggest that both testosterone cypionate (Deposteron) and stanozolol (Winstrol Depot) are associated with the 

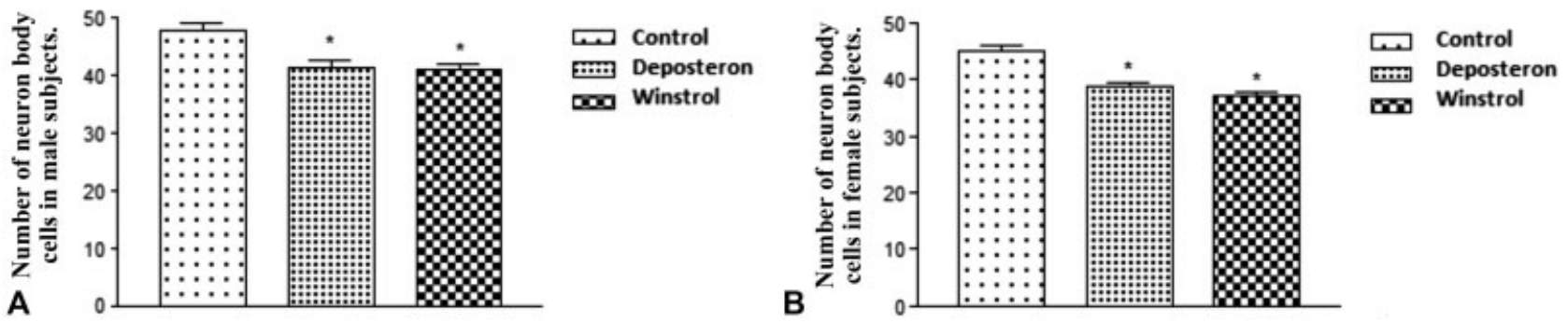

Fig. 4 Neuron body cells counting in the ventral posterior nucleus (VPN) of male and female animals. (A) shows comparative graphs of neuronal density in VPN of male mice in each analyzed experimental group $\left({ }^{*}=p<0.001\right)$ for testosterone cypionate and stanozolol in relation to the control group. (B) shows comparative graphs of neuronal density in VPN of female mice in each analyzed experimental group $\left({ }^{*}=p<0.001\right)$ for testosterone cypionate and stanozolol in relation to the control group.

Table 3 Mean of ventral posterior nucleus and percentage of reduction neuron cells quantification

\begin{tabular}{|l|l|l|}
\hline Groups & $\begin{array}{l}\text { Mean } \\
\text { BLA neuron cell }\end{array}$ & Percentage of reduction \\
\hline Male & \multicolumn{2}{|l|}{} \\
\hline Control & $45.00^{\mathrm{a}}$ & - \\
\hline Deposteron & $38.90^{\mathrm{b}}$ & $13.55 \%$ \\
\hline Winstrol & $37.04^{\mathrm{b}}$ & $17.68 \%$ \\
\hline Female & \multicolumn{2}{|l}{} \\
\hline Control & $48.03^{\mathrm{a}}$ & - \\
\hline Deposteron & $41.53^{\mathrm{b}}$ & $13.53 \%$ \\
\hline Winstrol & $41.15^{\mathrm{b}}$ & $14.32 \%$ \\
\hline
\end{tabular}

Abbreviation: BLA, basolateral amygdala.

Ventral posterior nucleus neuron cells quantification exhibited as mean value.

Different letters in superscript refer to statistical difference using Tukey test at the significance level of $5 \%$.

generation of anxiogenic responses. The stanozolol (Winstrol Depot) male animals group, as well as the testosterone cypionate (Deposteron) female animals group presented responses indicative of greater anxiety. In the first group, the animals presented a lower number of entries and a shorter staying time spent in the open arms of the EPM (more aversive area). In the second group, the animals had a longer staying time spent in the closed arms of the EPM (less aversive area) and a shorter staying time spent in the open arms of the EPM (more aversive area). No significant results were found for the testosterone cypionate (Deposteron) male animals group and stanozolol (Winstrol Depot) female animals group.

The generation of an anxiogenic response is in agreement with the results obtained in a study in which adult male $\mathrm{C} 57 \mathrm{Bl} / 6 \mathrm{~J}$ mice receiving a daily subcutaneous injection of $15 \mathrm{mg} / \mathrm{kg}$ of nandrolone decanoate presented an anxiogenic behavior in the EPM test after 19 days of treatment. ${ }^{20}$ Anxiogenic response in the EPM test was also observed in a study in which male Wistar rats received nandrolone decanoate $(5 \mathrm{mg} / \mathrm{kg}$ ) twice a week for 6 weeks and were submitted to the EPM test at the end of this period. $^{21}$
In another study, albino male mice receiving daily subcutaneous injections of nandrolone decanoate in the supraphysiological concentration of $15 \mathrm{mg} / \mathrm{kg}$ did not present changes in anxiety levels when submitted to the EPM test on the $14^{\text {th }}$ day of treatment ${ }^{[6]}$. Some authors have reported that the treatment of Long-Evans rats with subcutaneous testosterone propionate through silicone implants for prolonged administration of supraphysiological doses (6 days) promoted an increase in the open arms exploration of the $\mathrm{EPM}$, in relation to the control, indicating reduction on the level of anxiety. However, in the same study, treatment for 14 days did not promote anxiogenic effects. According to these authors, this variation of responses is due to the development of tolerance to AAS, a very common phenomenon in chronic users of psychoactive drugs. ${ }^{22}$

It has been demonstrated that serotonin activates inhibitory GABAergic interneurons in the amygdala, exerting a generalized inhibitory tonus on neuronal excitability, which suggests that serotonin functions as a brake mechanism that limits neuronal excitability. ${ }^{23}$ There is a possibility that an inhibitory effect of the AAS on the serotonergic system may contribute to a greater excitability of the amygdala, which, in turn, could be responsible for the behavioral responses observed in the AAS prolonged use. ${ }^{20}$

Since a high dose $(1 \mathrm{mg} / \mathrm{kg}$ ) of AAS binds to glucocorticoid receptors, ${ }^{21,24}$ the effects of these drugs could be related to their actions on these receptors. Glucocorticoids may act in the modulation of anxiety by their actions in the CNS, especially in the hippocampus. ${ }^{25}$

Some studies have attempted to correlate behavioral changes to the AAS effects on central serotonergic and GABAergic neurotransmission, among others, in several areas of the brain. ${ }^{26}$

In view of fact that there are synergistic interactions between glutamate and gonadal steroids coordinating several hypothalamic and limbic functions, the amygdaloid structures of treated groups, even with a lower number of neurons in relation to control group, may, through high local concentrations of AAS, stimulate glutamatergic transmission, increasing the excitatory signals in these neurons and keeping the aggressiveness responses statistically equal to those of control group. At the same time, it is also necessary to take into account the capacity of AAS to affect the gabaergic and serotoninergic transmissions, and may also 
result in a greater excitation of these neurons. In view of this situation, it is necessary to carry out new studies seeking to highlight how the AAS have led to these changes in behavioral responses.

In one study, it was observed that the AAS chronic use in mice has been shown to induce dose-, sex- and age-dependent changes in the GABA-receptor subunit gene expression in anterior brain areas. ${ }^{27}$ As observed in the present study, when evaluating neuronal density, it can be noted that both stanozolol and testosterone cypionate may lead to a decrease in the number of neuron body cells in mice. A statistically significant decrease in this number was observed in BLA of the stanozolol male animals group, testosterone cypionate and stanozolol female animals groups when compared with their respective control ones. We also observed the same result in the VPN of all experimental groups. These results are in agreement with previously published outcomes. ${ }^{28,29}$

In general, it seems that AAS physiological doses have the ability to play a neuroprotective role; however, when AAS is administered in high concentrations, they appear to exert a deleterious effect on neuron body cells, and most studies show an excitotoxic effect when using concentrations. The same was observed by some other authors, who found that pre-treatment with high doses of testosterone increased $\mathrm{N}$ methyl-D-aspartate (NMDA) toxicity. Low testosterone concentrations, on other hand, exerted neuroprotective role, but became neurotoxic in presence of aromatase inhibitors. 7,30

Another study has shown that hippocampal neurogenesis in adult male rats occurs via dihydrotestosterone (DHT) mediation, ${ }^{31}$ while other authors have demonstrated that in mouse hippocampal cell culture, high concentrations of testosterone increased the toxicity induced by millimolar concentrations of glutamate, whereas dehydroepiandrosterone (DHEA), a metabolite precursor of testosterone, exerted a neuroprotective role. ${ }^{32,33}$

In vivo studies, androgenic neurosteroids, such as DHEA, testosterone and DHT, play a protective role in the hippocampus against damage induced by excitotoxins, kainic acid and domoic acid. ${ }^{34,35}$ Neuroprotection was totally dependent on the availability of the enzyme aromatase, which converts testosterone to stradiol. ${ }^{36}$

Surprisingly, little is known about how androgens affect excitotoxic neuronal death, despite the large numbers of data obtained with female steroids. Excitotoxicity refers to a particular mechanism of neuronal death triggered by excessive stimulation of glutamatergic receptors. ${ }^{37,38}$

$\mathrm{N}$-methyl-D-aspartate receptors are located on the postsynaptic membrane of excitatory synapses and exhibit greater permeability to $\mathrm{Ca}^{2+}$ than $\alpha$-amino-3-hydroxy-5-methyl-4isoxazolepropionic acid (AMPA) and kainic acid (KA) receptors, a feature that gives them a more active role in neurotoxic mechanisms. When the postsynaptic membrane is in resting potential, the NMDA channels are blocked by a magnesium $\left(\mathrm{Mg}^{2+}\right)$ ion that prevents the influx of $\mathrm{Ca}^{2+}$ to the postsynaptic receptors. However, in postsynaptic depolarization (which may be caused by the activation of AMPA receptors, among others), $\mathrm{Mg}^{2+}$ ions are expelled from the NMDA channels, which thus allow the influx of $\mathrm{Ca}^{2+}$ in favor of its concentration gradient. ${ }^{39}$ In the cytosol, $\mathrm{Ca}^{2+}$ is an important second messenger and influences a large number of cellular functions, exerting a regulatory role in cellular proliferation and survival processes, as well as in cell death due to necrosis or apoptosis. ${ }^{40}$ The $\mathrm{Ca}^{2+}$ influx regulates membrane excitability and the intensity of synaptic transmission through the activation of intracellular signaling cascades dependent on this ion. Excessive concentrations of L-Glu in the synaptic cleft result in hyperstimulation of its receptors and an excessive $\mathrm{Ca}^{2+}$ entrance at the postsynaptic receptors, which, together with the release of $\mathrm{Ca}^{2+}$ from intracellular reserves, raise the $\mathrm{Ca}^{2+}$ concentration above the triggering threshold of regulatory mechanisms by activating the intracellular mechanisms of excitotoxicity that culminate in neuronal death. ${ }^{41}$

Other published data have shown that neuron body cells regulated by glutamate in the hypothalamus are direct targets of gonadal steroids, both androgens and estrogens. Thus, they can easily influence excitatory neurotransmission in these areas in a sexually dimorphic manner. ${ }^{42}$ The present work may explain the fact that testosterone cypionate led to a reduction in the number of neuron body cells in the BLA of female subjects but not in that of males.

\section{Conclusion}

The results obtained in the quantitative analyzes show that testosterone cypionate and stanozolol in supraphysiological doses are able to cause a significant reduction in the number of neuron body cells in the BLA and in the VPN of the medial amygdala of mice, and these results, added to the behavioral outcomes, may stimulate directly related anxiety-related emotional responses.

\section{Conflicts of Interest}

The authors have no conflicts of interest to declare.

\section{References}

1 Brower KJ. Anabolic steroids. Psychiatr Clin North Am 1993;16 (01):97-103

2 Clark AS, Fast AS. Comparison of the effects of 17 alpha-methyltestosterone, methandrostenolone, and nandrolone decanoate on the sexual behavior of castrated male rats. Behav Neurosci 1996; 110(06):1478-1486

3 Bahrke MS, Yesalis CE III, Wright JE. Psychological and behavioural effects of endogenous testosterone levels and anabolic-androgenic steroids among males. A review. Sports Med 1990;10(05): 303-337

4 Pope HG Jr, Katz DL. Affective and psychotic symptoms associated with anabolic steroid use. Am J Psychiatry 1988;145(04):487-490

5 Schulte A, Ernst H, Peters L, Heinrich U. Induction of squamous cell carcinomas in the mouse lung after long-term inhalation of polycyclic aromatic hydrocarbon-rich exhausts. Exp Toxicol Pathol 1994;45(07):415-421. Doi: 10.1016/S0940-2993(11)80369-6

6 Kalinine E, Zimmer ER, Zenki KC, et al. Nandrolone-induced aggressive behavior is associated with alterations in extracellular glutamate homeostasis in mice. Horm Behav 2014;66(02): 383-392. Doi: 10.1016/j.yhbeh.2014.06.005

7 Estrada M, Varshney A, Ehrlich BE. Elevated testosterone induces apoptosis in neuronal cells.J Biol Chem 2006;281(35):25492-25501. Doi: 10.1074/jbc.M603193200 
8 Talih F, Fattal O, Malone D Jr. Anabolic steroid abuse: psychiatric and physical costs. Cleve Clin J Med 2007;74(05):341-344, 346, 349-352

9 Tucci P, Morgese MG, Colaianna M, et al. Neurochemical consequence of steroid abuse: stanozolol-induced monoaminergic changes. Steroids 2012;77(03):269-275. Doi: 10.1016/j.steroids.2011.12.014

10 Henderson LP, Penatti CA, Jones BL, Yang P, Clark AS. Anabolic androgenic steroids and forebrain GABAergic transmission. Neuroscience 2006;138(03):793-799. Doi: 10.1016/j.neuroscience.2005.08.039

11 Carobrez AP, Bertoglio LJ. Ethological and temporal analyses of anxiety-like behavior: the elevated plus-maze model 20 years on. Neurosci Biobehav Rev 2005;29(08):1193-1205. Doi: 10.1016/j. neubiorev.2005.04.017

12 Lister RG. The use of a plus-maze to measure anxiety in the mouse. Psychopharmacology (Berl) 1987;92(02):180-185

13 Ribeiro CM, Silva DK, Damião B, et al. Análise quantitativa de células de Purkinje em camundongos sob o uso dos esteroides anabolizantes. Revista Neurociências 2014;22(03):432-437. Doi: 10.4181/RNC.2014.22.03.969.6p

14 von Bartheld CS, Bahney J, Herculano-Houzel S. The search for true numbers of neurons and glial cells in the human brain: A review of 150 years of cell counting. J Comp Neurol 2016;524(18): 3865-3895https://doi.org/doi. Doi: 10.1002/cne.24040

15 Franklin KBJ, Paxinos G. Paxinos and Franklin's The mouse brain in stereotaxic coordinates, 3rd edn. Academic Press, an imprint of ElsevierNew York

16 Kádár A, Sánchez E, Wittmann G, et al. Distribution of hypophysiotropic thyrotropin-releasing hormone (TRH)-synthesizing neurons in the hypothalamic paraventricular nucleus of the mouse. J Comp Neurol 2010;518(19):3948-3961https://doi.org/ doi. Doi: 10.1002/cne.22432

17 Mandarim-de-Lacerda CA. Stereological tools in biomedical research. An Acad Bras Cienc 2003;75(04):469-486

18 Boyce RW, Dorph-Petersen KA, Lyck L, Gundersen HJ. Design-based stereology: introduction to basic concepts and practical approaches for estimation of cell number. Toxicol Pathol 2010;38(07):1011-1025https://doi.org/doi. Doi: 10.1177/0192623310385140

19 Mühlfeld C, Papadakis T, Krasteva G, Nyengaard JR, Hahn U, Kummer W. An unbiased stereological method for efficiently quantifying the innervation of the heart and other organs based on total length estimations. J Appl Physiol (1985) 2010;108(05): 1402-1409https://doi.org/doi:10.1152/japplphysiol.01013.2009

20 Ambar G, Chiavegatto S. Anabolic-androgenic steroid treatment induces behavioral disinhibition and downregulation of serotonin receptor messenger RNA in the prefrontal cortex and amygdala of male mice. Genes Brain Behav 2009;8(02):161-173. Doi: 10.1111/j.1601-183X.2008.00458.x

21 Rocha VM, Calil CM, Ferreira R, Moura MJ, Marcondes FK. Influence of anabolic steroid on anxiety levels in sedentary male rats. Stress 2007;10(04):326-331. Doi: 10.1080/10253890701281344

22 Bitran D, Kellogg CK, Hilvers RJ. Treatment with an anabolicandrogenic steroid affects anxiety-related behavior and alters the sensitivity of cortical GABAA receptors in the rat. Horm Behav 1993;27(04):568-583. Doi: 10.1006/hbeh.1993.1041

23 Rainnie DG. Serotonergic modulation of neurotransmission in the rat basolateral amygdala. J Neurophysiol 1999;82(01):69-85

24 Friedel A, Geyer H, Kamber M, et al. 17beta-hydroxy-5alphaandrost-1-en-3-one (1-testosterone) is a potent androgen with anabolic properties. Toxicol Lett 2006;165(02):149-155. Doi: $10.1016 /$ j.toxlet.2006.03.001
25 Oliveira M, Bessa JM, Mesquita A, et al. Induction of a hyperanxious state by antenatal dexamethasone: a case for less detrimental natural corticosteroids. Biol Psychiatry 2006;59(09): 844-852. Doi: 10.1016/j.biopsych.2005.08.020

26 Hallberg M, Johansson P, Kindlundh AM, Nyberg F. Anabolicandrogenic steroids affect the content of substance $P$ and substance $\mathrm{P}(1-7)$ in the rat brain. Peptides 2000;21(06):845-852

27 McIntyre KL, Porter DM, Henderson LP. Anabolic androgenic steroids induce age-, sex-, and dose-dependent changes in GABA(A) receptor subunit mRNAs in the mouse forebrain. Neuropharmacology 2002;43(04):634-645

28 Damião B, Souza GG, Nogueira DA, et al. Quantificação de Corpos de Neurônios em Camundongos Submetidos ao Uso de Esteroides Anabolizantes. Revista de Neurociências 2012;20(01):68-72

29 Freitas AC, Damiao B, Alves DM, et al. Efeitos dos anabolizantes sobre a densidade de neurônios dos núcleos da base. Rev Bras Med Esporte 2017;23(03):213-216. Doi: 10.1590/1517869220172303151688

30 Orlando R, Caruso A, Molinaro G, et al. Nanomolar concentrations of anabolic-androgenic steroids amplify excitotoxic neuronal death in mixed mouse cortical cultures. Brain Res 2007; 1165:21-29. Doi: 10.1016/j.brainres.2007.06.047

31 Okamoto $\mathrm{M}$, Hojo $\mathrm{Y}$, Inoue $\mathrm{K}$, et al. Mild exercise increases dihydrotestosterone in hippocampus providing evidence for androgenic mediation of neurogenesis. Proc Natl Acad Sci U S A 2012;109(32):13100-13105. Doi: 10.1073/pnas.1210023109

32 Yang P, Lones BL, Henderson LP. Mechanisms of anabolic androgenic steroid modulation of GABAA receptors. Neuropharmacology 2002;43(04):619-633. Doi: 10.1016/S0028-3908(02) 00155-7

33 Cardounel A, Regelson W, Kalimi M. Dehydroepiandrosterone protects hippocampal neurons against neurotoxin-induced cell death: mechanism of action. Proc Soc Exp Biol Med 1999;222(02): 145-149

34 Frye CA, Reed TA. Androgenic neurosteroids: anti-seizure effects in an animal model of epilepsy. Psychoneuroendocrinology 1998; 23(04):385-399

35 Ramsden M, Shin TM, Pike CJ. Androgens modulate neuronal vulnerability to kainate lesion. Neuroscience 2003;122(03):573-578

36 Azcoitia I, Sierra A, Veiga S, Honda S, Harada N, Garcia-Segura LM. Brain aromatase is neuroprotective. J Neurobiol 2001;47(04): 318-329

37 [REMOVED HYPERLINK FIELD]Choi DW. Glutamate neurotoxicity and diseases of the nervous system. Neuron 1988;1(08):623-634

38 Rothman SM, Olney JW. Excitotoxicity and the NMDA receptorstill lethal after eight years. Trends Neurosci 1995;18(02):57-58

39 Kubo M, Ito E. Structural dynamics of an ionotropic glutamate receptor. Proteins 2004;56(03):411-419. Doi: 10.1002/ prot.20154

40 Orrenius S, Ankarcrona M, Nicotera P. Mechanisms of calciumrelated cell death. Adv Neurol 1996;71:137-149, discussion 149151

41 Sattler R, Tymianski M. Molecular mechanisms of calcium-dependent excitotoxicity. J Mol Med (Berl) 2000;78(01):3-13. Doi: 10.1007/s001090000077

42 Diano S, Naftolin F, Horvath TL. Gonadal steroids target AMPA glutamate receptor-containing neurons in the rat hypothalamus, septum and amygdala: a morphological and biochemical study. Endocrinology 1997;138(02):778-789. Doi: 10.1210/ endo.138.2.4937 